\title{
Microwave alkylation of lithium tetrazolate
}

\author{
Danny Müller ${ }^{1}$ (i) $\cdot$ Christian Knoll $^{1} \cdot$ Peter Weinberger $^{1}$
}

Received: 29 September 2016/Accepted: 25 October 2016/Published online: 30 November 2016

(C) The Author(s) 2016. This article is published with open access at Springerlink.com

\begin{abstract}
N1-substituted tetrazoles are interesting ligands in transition metal coordination chemistry, especially in the field of spin crossover. Their synthesis is performed in most cases according to the Franke-synthesis, using a primary amine as reagent introducing the substitution pattern. To enhance flexibility in means of substrate scope, we developed a new protocol based on alkylation of lithium tetrazolate with alkyl bromides. The N1-N2 isomerism of the tetrazole during the alkylation was successfully suppressed by use of highly pure lithium tetrazolate and 30 vol.\% aqueous ethanol as solvent, leading to pure N1substituted products. The feasibility of this reaction was demonstrated by a selection of different substrates. Graphical abstract
\end{abstract}

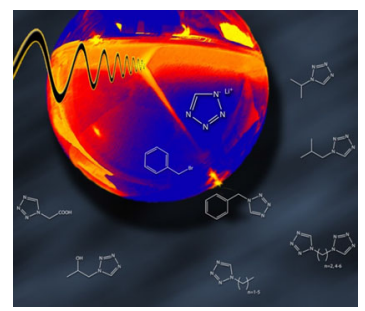

Keywords N1-Tetrazole · Heterocycles · Basicity · Solvent effect $\cdot \mathrm{N}$-Heterocyclic ligands $\cdot$ Spin crossover

Danny Müller

danny.mueller@tuwien.ac.at

1 Institute of Applied Synthetic Chemistry, TU Wien, Getreidemarkt 9/163-AC, 1060 Vienna, Austria

\section{Introduction}

Tetrazoles are five-membered $6 \pi$-aromatic heterocyclic compounds and, in the case of the unsubstituted form, with the notably high nitrogen content of $79.98 \%$. Tetrazoles allow for three different isomers (Scheme 1), among which only the $5 H$-tetrazole being non-aromatic [1].

Depending on the substituent, substituted tetrazoles can undergo several forms of tautomerism: apart from the ringopening within the azido-imine-tautomerism, C5-alkyl or unsubstituted rings undergo changes in the substitution pattern via annular-tautomerism [2], whereas an electronegative substituent in the C5-position favours aminoimino-tautomerism [3].

The very first reported employments of tetrazoles were as colorants, photographical chemicals, explosives, propellants, and agrochemicals [4-6]. Since the 1960s, tetrazoles witnessed a renaissance but now with their application strongly depending on their isomeric form. In the medicinal chemistry, N2- and especially C5-substituted tetrazoles are used as carboxylic acid bioisosteres [7], as structural motif for angiotensin blockers [8-10], as activator in oligonucleotide synthesis [11] or in the MTTassay, determining the metabolic cell activity by reduction of a tetrazole-dye to a formazan by living cells [12].

In contrast, N1-substituted tetrazoles are mainly used as ligands in inorganic coordination chemistry for transition metal complexes. One major application there is the field of spin-crossover materials. The spin crossover effect is known, since over 80 years $[13,14]$, but with the discovery of the light-induced excited spin state trapping effect (LIESSTeffect) $[15,16]$ in 1984, spin crossover complexes arouse nearly overnight notable interest as switchable components for data storage [17, 18], sensor materials [19], and miniaturization of magneto-optical devices [20,21]. 


\section{Scheme 1}

$$
{ }_{N}=N
$$<smiles>C=C</smiles><smiles>c1nn[nH]n1</smiles><smiles>C=C</smiles>

$1 H$-tetrazole

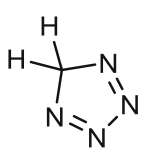

$5 \mathrm{H}$-tetrazole

Two of the earliest publications about spin-transition in N1-tetrazole-complexes were the reports on 1-alkyltetrazole-complexes by Franke [22, 23]. Since these first publications, tetrazoles were used in many investigations, as variation of crystallization [24, 25], solvent [25], the anion and its size [26], spacer-substitution [27, 28] and length [28], or the number of coordinating sites [27, 28] provides independent different access-points allowing for rational design of the ligand system.

Different synthetic approaches towards N1-substituted tetrazoles were established so far. They are based on [2+3]-cycloaddition of isonitriles and azides [4-6], functionalization of $1 H$-tetrazole using tosylates [29], or a cycloaddition of sodium azide, triethyl orthoformate, and a primary amine known as the Franke-synthesis [23]. Although the Franke-synthesis is by far the most common, all approaches have, in common, moderate yields. A more challenging weakness of these approaches is the reagent introducing the substitution pattern: only a few isonitriles and tosylates are commercially available. Regarding the primary amines, the spectrum of commercial materials is notably larger, but many substrates need to be purified in advanced or-in the case of a non-available amine precursor-synthesized in the lab. Therefore, an approach using alternative substrates was attempted. Main focus points for this purpose were first, a larger commercial spectrum of available substitution patterns which are, in best case, also cheaper than amines. Second, the use of bench-stable and, if necessary, easily prepared precursors, and third, shorter reaction times and possibly higher yields in the tetrazole formation.

For this purpose, we decided to focus on the reaction of alkali tetrazolates $(\mathrm{Tz})$ with alkyl halides.

\section{Results and discussion}

The complete series of alkali-tetrazolate salts was reported in 2008 by Klapötke et al. [30]. All of these salts are relatively stable compounds and easily prepared in good yields by neutralization of a $1 \mathrm{H}$-tetrazole solution with the corresponding base.

Regarding the alkylation reaction of tetrazoles, a nonnegligible difficulty is found in its tendency towards isomerization: For many substitution reactions of tetrazoles, it

is known that a mixture of the $\mathrm{N} 1-\mathrm{N} 2$ isomeric products is obtained [1].

To gain a first impression on the feasibility of the attempted alkylation reaction in a first screening series, 1-chlorobutane, 1-bromobutane, and 1-iodobutane were reacted for $6 \mathrm{~h}$ at 25,75 , and $150{ }^{\circ} \mathrm{C}$ with the lithium, sodium, and potassium salts of $1 H$-tetrazole. For the reaction, sealed vessels with THF as solvent were used (Scheme 2). The tetrazolate salts were prepared according to the literature. The isomer ratio is easily determined by ${ }^{1} \mathrm{H}$ NMR, as the tetrazolic $\mathrm{CH}$ and the signals of the adjacent $\mathrm{CH}_{\mathrm{x}}$-groups are significantly shifted to low field in the case of the N2-isomer.

Whereas for room temperature no reaction was evidenced, for the samples at elevated temperatures, 1-butyl$1 H$-tetrazole as alkylation product was isolated. Independent from the used tetrazolate, for all reactions at $150{ }^{\circ} \mathrm{C}$, 1:1 mixtures of the $\mathrm{N} 1$ and $\mathrm{N} 2$ isomer were identified. The best results were achieved at $75^{\circ} \mathrm{C}$, where for the first time, a clear tendency towards the desired N1 isomer was observed: LiTz yielded a 3:1 mixture of $\mathrm{N} 1$ and $\mathrm{N} 2$ isomer (NaTz and $\mathrm{KTz}$ both 1:1). It should be mentioned that in all experiments, the 1-iodobutane behaved worse than the corresponding chloride and bromide, as coloured products along untraceable by-products were isolated.

In a second series of experiments, LiTz was reacted with 1-bromobutane in methanol for $6 \mathrm{~h}$ at $130{ }^{\circ} \mathrm{C}$ in a sealed vessel in presence of $10 \mathrm{~mol} \% \mathrm{LiOH}$ as additional base and once as control experiment without. The presence of base turned out to be disadvantageous, as a 1:1.5 ratio of N1/N2 isomers was found. In contrast, the use of $\mathrm{MeOH}$ led to $49 \%$ isolated yield of 1-butyl- $1 H$-tetrazole, contaminated by only $11 \% \mathrm{~N} 2$-isomer.

For a detailed screening of temperature, reaction time, and stoichiometry on basis of these first results, the combination of $\mathrm{LiTz}$ and 1-bromobutane in methanol was chosen. To decrease the reaction time and enlarge the temperature window, all further reactions were performed using a laboratory microwave oven.

As the amount of pure N1-alkylation was irreproducible under all investigated circumstances, the quality of the lithium tetrazolate was identified to be the only variable among these experiments. By determination of the $\mathrm{pH}$ value and use of powder $\mathrm{X}$-ray diffraction ( $\mathrm{P}-\mathrm{XRD}$ )

\section{Scheme 2}

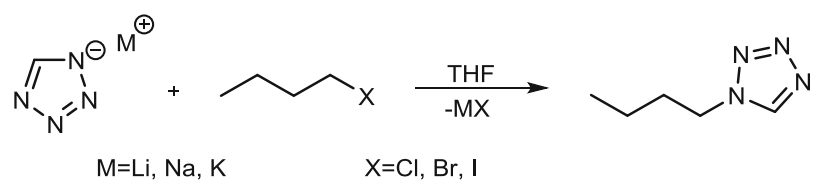


<smiles>COC(O)[C@H](OC)c1cn([O-])nn1</smiles>

analysis, for the so far used batches of $\mathrm{LiTz}$, varying amounts of contamination with $\mathrm{LiOH} \cdot \mathrm{H}_{2} \mathrm{O}$ and $\mathrm{Li}_{2} \mathrm{CO}_{3}$ were found. As the used anhydrous $\mathrm{LiOH}$ is very sensitive towards moisture and atmospheric $\mathrm{CO}_{2}$, an alternative procedure for the LiTz-synthesis was developed. By the use of a freshly prepared LiOMe-solution in $\mathrm{MeOH}$ and subsequent removal of unreacted $1 H$-tetrazole by extraction with hot anhydrous isopropanol, a reproducibly pure LiTz could be obtained (Scheme 3).

The use of high temperatures (varying conditions between 140 and $200{ }^{\circ} \mathrm{C}$ ) and the use of methanol yielded rather irreproducible results, leading to a systematic optimization regarding reaction temperature and polarity of the solvent. To enhance reactivity and reduce reaction time, the addition of $10 \mathrm{~mol} \%$ of lithium iodide hydrate was found to be advantageous. With constant yield and isomer ratio, the reaction temperature could be decreased to $100{ }^{\circ} \mathrm{C}$ and reaction times of $45 \mathrm{~min}$. Samples reacted for longer times in the microwave showed increasing N2-isomer fractions.

Very promising results were obtained due to the variation of the solvent polarity. The use of anhydrous ethanol yielded reproducible mixtures with $\mathrm{N} 2$ contents between 20 and $43 \%$. The use of water instead of methanol led to a negligible product formation, promoting the formation of intractable products. By the use of water-ethanol mixtures, finally, the desired selectivity could be obtained. As shown in Fig. 1, the amount of N2-isomer decreases with increasing water content. Using $30 \% \mathrm{v} / \mathrm{v}$ ethanol-water mixtures led, reproducibly, to pure N1-isomeric products. By means of NMR and IR spectroscopy, no N2-isomer formation was detected.

Summarizing the optimization procedure, the best results were achieved using a mixture of fresh lithium tetrazolate and $\mathrm{R}-\mathrm{Br}$ substrate $\left(1-3 \mathrm{mmol}\right.$ per $\mathrm{cm}^{3}$ of solvent) in a solution of $30 \mathrm{vol} \%$ ethanol-water mixture, reacted for $45 \mathrm{~min}$ under microwave conditions at $100{ }^{\circ} \mathrm{C}$.

Once proper conditions were found, the reaction was repeated with different substrates. Yields and structure of the investigated materials are given in Table 1.

For the selection of substrates presented in Table 1, the conditions developed during the screening-process at hand of the reaction of 1-bromobutane with $\mathrm{LiTz}$ were successfully applied. The formation of the corresponding N2isomer was not evidenced in any case. Contrasting the newly developed substitution protocol with the so far

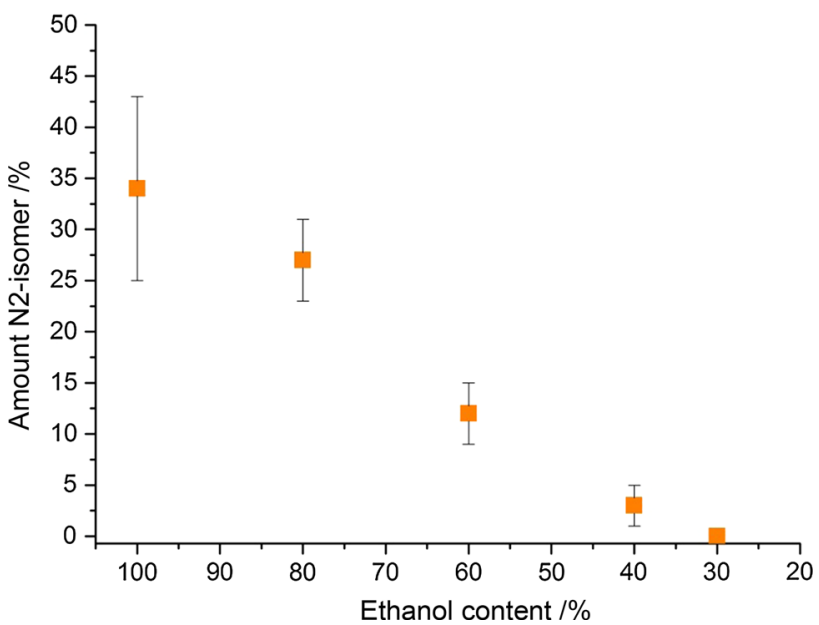

Fig. 1 Correlation between N2-isomer concentration and ethanolwater ratio

commonly used Franke-synthesis, the yields could not be notably enhanced for all investigated cases. Moreover, the main advantages of the alkylation protocol are shorter reaction times and, especially, the use of bromides as cheap commercially available starting materials with a broader structural variety than for amines. The alkylation protocol cannot be seen as replacement for the Franke reaction, but notably enhances the flexibility regarding synthetic approaches to desired target structures.

\section{Conclusion}

Based on the alkylation of alkali tetrazolates, within this work, a novel approach to N1-functionalized tetrazoles was developed. The aim was to establish a protocol using bench-stable commercial substrates, which are cheaper and available for a broader scope of substrates than amines are. These demands were satisfied by the alkylation of lithium tetrazolate with alkyl bromides.

The major difficulty for alkylation of the tetrazole was the N1-N2 isomerism. Within several screening steps, the purity of the lithium tetrazolate, as well as the polarity of the solvent were identified as crucial parameters. A modified protocol using lithium methanolate guarantees for a reproducibly high quality of the LiTz. In combination with $30 \mathrm{vol} . \%$ aqueous ethanol as solvent, this protocol allows for quantitative suppression of N2-isomer formation. The reaction was optimized using microwave conditions, leading finally to a protocol, which allows for good yields after 45-min reaction time at $100{ }^{\circ} \mathrm{C}$. Whereas longer reaction times do not significantly increase the yield, they promote side reactions.

The alkylation reaction leads in a very short time to a broad spectrum of interesting ligands, as could be shown 
Table 1 Target structures and isolated yields used in the substrate screening (conditions and used substrates are given in the "Experimental section")

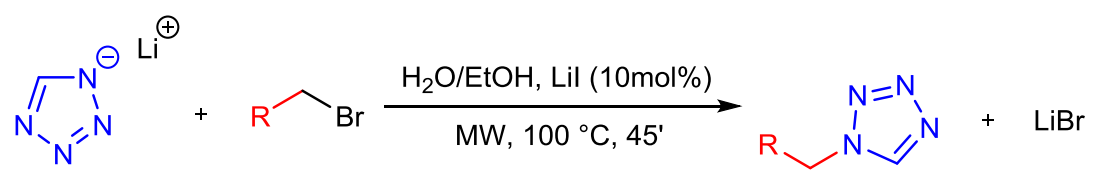

(2)

by several examples within this work. In summary, it was possible to modify, through this new approach, the ligand synthesis for N1-substituted tetrazoles in an effective way. This allows, in the future, for significantly higher throughput and an optimized design of interesting target structures for spin-crossover materials based on N1-substituted tetrazoles.

\section{Experimental}

For all experiments, reagents and solvents were commercially obtained from Sigma-Aldrich and used as supplied. Unless otherwise stated, all reactions were performed under normal aerobic conditions.

${ }^{1} \mathrm{H}$ and ${ }^{13} \mathrm{C}\{1 \mathrm{H}\}$ NMR spectra were recorded on a Bruker Avance UltraShield 400 spectrometer with broadband probe head. All NMR chemical shifts are reported in ppm; ${ }^{1} \mathrm{H}$ and ${ }^{13} \mathrm{C}$ shifts are referenced to the residual solvent resonance. Mid-range infrared spectra were recorded in ATR technique within the range of $4000-450 \mathrm{~cm}^{-1}$ using a PerkinElmer Spectrum Two FTIR spectrometer with an UATR accessory attached. If not otherwise stated, the background was measured with opened anvil versus ambient air. The powder X-ray diffraction measurements were carried out on a PANalytical X'Pert diffractometer in Bragg-Brentano geometry using $\mathrm{Cu} \mathrm{K}_{\alpha 1,2}$ radiation, an $\mathrm{X}$ 'Celerator linear detector with a $\mathrm{Ni}-$ filter, sample spinning with back loading zero background sample holders and $2 \theta=4^{\circ}-90^{\circ}, T=297 \mathrm{~K}$ at the $\mathrm{X}$-ray Center at TU Wien. The diffractograms were evaluated using the PANalytical program suite HighScore Plus v3.0d. A background correction and a $\mathrm{K}_{\alpha 2}$ strip were performed.

Warning: Tetrazoles and its derivatives are potential explosive and shock sensitive compounds; therefore handle with care. Proper protective measures should be taken [31, 32].

1H-tetrazole (1)

$\mathrm{NH}_{4} \mathrm{Cl}$ (53.49 g, 1 mol, 1 eq.) and $97.51 \mathrm{~g} \mathrm{NaN}_{3}$ (1.5 mol, 1.5 eq.) were suspended in $258 \mathrm{~cm}^{3}$ triethyl orthoformate (1.55 mol, 1.55 eq.) and $500 \mathrm{~cm}^{3}$ acetic acid. The reaction mixture was stirred for $18 \mathrm{~h}$ at $95{ }^{\circ} \mathrm{C}$ and filtrated after cooling. After evaporation to dryness, the solid residue was 
extracted with $450 \mathrm{~cm}^{3}$ of boiling isopropanol. This step was repeated once. The off-white residue after evaporation of the combined isopropanol fractions was recrystallized from ethanol. Yield: $42.4 \mathrm{~g}(60.5 \%)$. The spectroscopic properties $\left({ }^{1} \mathrm{H}\right.$ NMR, ${ }^{13} \mathrm{C}\{1 \mathrm{H}\}$ NMR, and MIR) were found to be identical with the ones described in Ref. [30].

\section{Lithium tetrazolate (2)}

Lithium granulate ( $2 \mathrm{~g}, 0.29 \mathrm{~mol}, 1$ eq.) was dissolved under cooling in $250 \mathrm{~cm}^{3}$ dry methanol. To the lithium methoxide solution, slowly, $22.2 \mathrm{~g}$ of $1 H$-tetrazole ( $0.32 \mathrm{~mol}, 1.1$ eq.) was added. The suspension was stirred for $1 \mathrm{~h}$ at room temperature. After filtration, the lithium tetrazolate was dried in vacuum and stored under inert gas. Yield: $18.3 \mathrm{~g}(83.6 \%)$. The spectroscopic properties $\left({ }^{1} \mathrm{H}\right.$ NMR, ${ }^{13} \mathrm{C}\{1 \mathrm{H}\}$ NMR, and MIR) were found to be identical with the ones described in Ref. [30].

\section{General procedure for microwave alkylations}

Freshly prepared lithium tetrazolate $(228 \mathrm{mg}, 3 \mathrm{mmol}$, 1 eq.) and $3 \mathrm{mmol}$ of the alkyl bromide were dissolved in $3 \mathrm{~cm}^{3}$ of $30 \% \mathrm{v} / \mathrm{v}$ ethanol in a microwave vial. Lithium iodide hydrate $(45.5 \mathrm{mg}, 0.3 \mathrm{mmol}, 0.1 \mathrm{eq}$.) was added. The mixture was immediately reacted in the microwave at $100{ }^{\circ} \mathrm{C}$ for $45 \mathrm{~min}$. Two different workup strategies were used:

Workup A The reaction mixture was diluted with $5 \mathrm{~cm}^{3}$ water and, afterwards, extracted twice with $10 \mathrm{~cm}^{3}$ of hexane to remove the eventually formed $\mathrm{N} 2$-isomer. Afterwards, the extraction was repeated three times with $10 \mathrm{~cm}^{3}$ of ethyl acetate each. The combined organic phases were dried over $\mathrm{MgSO}_{4}$ and evaporated to yield the product.

Workup $B$ The reaction mixture was filtered through a thin layer of silica gel and evaporated. The solid residue was triturated with $30 \mathrm{~cm}^{3}$ ethyl acetate and evaporated, yielding the product.

\section{Indicated yields refer to isolated yields}

\section{1-Ethyl-1H-tetrazole (3)}

Lithium tetrazolate and 1-bromoethane were used as reagents. Workup A, product obtained as colourless oil. Yield: $180.43 \mathrm{mg}$ (61.3\%). The spectroscopic properties $\left({ }^{1} \mathrm{H}\right.$ NMR, ${ }^{13} \mathrm{C}\{1 \mathrm{H}\}$ NMR, and MIR) were found to be identical with the ones described in Ref. [28].

\section{1-Propyl-1H-tetrazole (4)}

Lithium tetrazolate and 1-bromopropane were used as reagents. Workup A, product obtained as colourless oil. Yield: $189.74 \mathrm{mg}$ (56.4\%). The spectroscopic properties $\left({ }^{1} \mathrm{H}\right.$ NMR, ${ }^{13} \mathrm{C}\{1 \mathrm{H}\}$ NMR, and MIR) were found to be identical with the ones described in Ref. [28].

\section{1-Butyl-1H-tetrazole (5)}

Lithium tetrazolate and 1-bromobutane were used as reagents. Workup A, product obtained as colourless oil. Yield: $245.26 \mathrm{mg}(64 . \%)$. The spectroscopic properties $\left({ }^{1} \mathrm{H}\right.$ NMR, ${ }^{13} \mathrm{C}\{1 \mathrm{H}\}$ NMR, and MIR) were found to be identical with the ones described in Ref. [28].

\section{1-Pentyl-1H-tetrazole (6)}

Lithium tetrazolate and 1-bromopentane were used as reagents. Workup A, product obtained as colourless oil. Yield: $202.29 \mathrm{mg}(48.1 \%)$. The spectroscopic properties $\left({ }^{1} \mathrm{H}\right.$ NMR, ${ }^{13} \mathrm{C}\{1 \mathrm{H}\}$ NMR, and MIR) were found to be identical with the ones described in Ref. [33].

\section{1-Hexyl-1H-tetrazole (7)}

Lithium tetrazolate and 1-bromohexane were used as reagents. Workup A, product obtained as colourless oil. Yield: $265.11 \mathrm{mg}$ (57.3\%). The spectroscopic properties $\left({ }^{1} \mathrm{H}\right.$ NMR, ${ }^{13} \mathrm{C}\{1 \mathrm{H}\} \mathrm{NMR}$, and MIR) were found to be identical with the ones described in Ref. [33].

\section{1,2-Bis(tetrazol-1-yl)ethane (8)}

Lithium tetrazolate and 1,2-dibromoethane were used as reagents. Workup B, product obtained as white solid. Yield: $275.14 \mathrm{mg}(55.2 \%)$. The spectroscopic properties $\left({ }^{1} \mathrm{H}\right.$ NMR, ${ }^{13} \mathrm{C}\{1 \mathrm{H}\}$ NMR, and MIR) were found to be identical with the ones described in Ref. [34].

\section{1,4-Bis(tetrazol-1-yl)butane (9)}

Lithium tetrazolate and 1,4-dibromobutane were used as reagents. Workup B, product obtained as off-white solid. Yield: $330.33 \mathrm{mg}$ (56.7\%). The spectroscopic properties $\left({ }^{1} \mathrm{H}\right.$ NMR, ${ }^{13} \mathrm{C}\{1 \mathrm{H}\}$ NMR, and MIR) were found to be identical with the ones described in Ref. [35].

\section{1,5-Bis(tetrazol-1-yl)pentane (10)}

Lithium tetrazolate and 1,5-dibromopentane were used as reagents. Workup $\mathrm{B}$, product obtained as white solid. Yield: $403.55 \mathrm{mg}$ (64.6\%). The spectroscopic properties $\left({ }^{1} \mathrm{H}\right.$ NMR, ${ }^{13} \mathrm{C}\{1 \mathrm{H}\} \mathrm{NMR}$, and MIR) were found to be identical with the ones described in Ref. [36].

\section{1,6-Bis(tetrazol-1-yl)hexane (11)}

Lithium tetrazolate and 1,6-dibromohexane were used as reagents. Workup B, product obtained as beige solid. Yield: $349.39 \mathrm{mg}(52.4 \%)$. The spectroscopic properties $\left({ }^{1} \mathrm{H}\right.$ NMR, ${ }^{13} \mathrm{C}\{1 \mathrm{H}\}$ NMR, and MIR) were found to be identical with the ones described in Ref. [24].

\section{1-Isopropyl-1H-tetrazole (12)}

Lithium tetrazolate and 2-bromopropane were used as reagents. Workup A, product obtained as colourless oil. Yield: $148.36 \mathrm{mg}$ (44.1\%). The spectroscopic properties 
( ${ }^{1} \mathrm{H}$ NMR, ${ }^{13} \mathrm{C}\{1 \mathrm{H}\} \mathrm{NMR}$, and MIR) were found to be identical with the ones described in Ref. [37].

\section{1-Isobutyl-1H-tetrazole (13)}

Lithium tetrazolate and 1-bromo-2-methylpropane were used as reagents. Workup A, product obtained as colourless oil. Yield: $183.18 \mathrm{mg}(48.4 \%)$. The spectroscopic properties $\left({ }^{1} \mathrm{H}\right.$ NMR, ${ }^{13} \mathrm{C}\{1 \mathrm{H}\} \mathrm{NMR}$, and MIR) were found to be identical with the ones described in Ref. [37].

\section{1-Benzyl-1H-tetrazole (14)}

Lithium tetrazolate and (bromomethyl)benzene were used as reagents. Workup B, product obtained as white solid. Yield: $200.39 \mathrm{mg}(41.7 \%)$. The spectroscopic properties $\left({ }^{1} \mathrm{H}\right.$ NMR, ${ }^{13} \mathrm{C}\{1 \mathrm{H}\} \mathrm{NMR}$, and MIR) were found to be identical with the ones described in Ref. [38].

\section{1-(1H-Tetrazol-1-yl)propan-2-ol (15)}

Lithium tetrazolate and 1-bromopropan-2-ol were used as reagents. Workup A, product obtained as colourless oil. Yield: $219.09 \mathrm{mg}(64 \%)$. The spectroscopic properties $\left({ }^{1} \mathrm{H}\right.$ NMR, ${ }^{13} \mathrm{C}\{1 \mathrm{H}\} \mathrm{NMR}$, and MIR) were found to be identical with the ones described in Ref. [1, 4].

\section{2-(1H-Tetrazol-1-yl)acetic acid (16)}

Lithium tetrazolate and 2-bromoacetic acid were used as reagents. Workup B, product obtained as white solid. Before evaporation of the crude reaction mixture, the solution was acidified using hydrochloric acid. For the final extraction, isopropanol instead of ethyl acetate was used. Yield: $129.11 \mathrm{mg}$ (33.6\%). The spectroscopic properties $\left({ }^{1} \mathrm{H} \mathrm{NMR},{ }^{13} \mathrm{C}\{1 \mathrm{H}\} \mathrm{NMR}\right.$, and MIR) were found to be identical with the ones described in Ref. [39].

Acknowledgements Open access funding provided by Austrian Science Fund (FWF). We acknowledge financial support of the Austrian Science Fund (FWF Der Wissenschaftsfond) Project P24955-N28. This work was performed in the framework of the Corporation in Science and Technology (COST) action CM1305 Explicit Control Over Spin-states in Technology and Biochemistry (ECOSTBio). The X-ray center (XRC) of TU Wien (head: Klaudia Hradil) provided access to the powder X-ray diffractometer.

Open Access This article is distributed under the terms of the Creative Commons Attribution 4.0 International License (http:// creativecommons.org/licenses/by/4.0/), which permits unrestricted use, distribution, and reproduction in any medium, provided you give appropriate credit to the original author(s) and the source, provide a link to the Creative Commons license, and indicate if changes were made.

\section{References}

1. Meier H (1994) Tetrazole. Houben Weyl, Methods of organic chemistry, E-series, vol E8d. Thieme Chemistry, Stuttgart

2. Moore DW, Whittaker AG (1960) J Am Chem Soc 82:5007
3. Lieber E, Rao CNR, Pillai CN, Ramachandran J, Hites RD (1958) Can J Chem 36:801

4. Benson FR (1967) In: Elderfield RC (ed) Heterocyclic compounds. Wiley, New York

5. Butler R (1997) In: Boulton AR (ed) Advances in heterocyclic chemistry. Academic Press, New York

6. Rathsburg H (1921) Explosives. GB 185555, Sep 14, 1922; (1923) Chem Abstr 17:6365

7. Malik MA, Wani MY, Al-Thabaiti SA, Shiekh RA (2013) J Incl Phenom Macro 78:15

8. Kawata T, Hashimoto S, Koike T (1996) J Pharmacol Exp Ther 277:572

9. Kim JH, Lee JH, Paik SH, Kim JH, Chi YH (2012) Arch Pharm Res 35:1123

10. Velasquez MT (1996) Arch Fam Med 5:351

11. Berner S, Mūhlegger K, Seliger H (1989) Nucleic Acids Res 17:853

12. Berridge MV, Herst PM, Tan AS (2005) Biotechnol Annu Rev 11:127

13. Cambi L, Szegö L (1931) Ber Dtsch Chem Ges 64:2591

14. Cambi L, Szegö L (1933) Ber Dtsch Chem Ges 66:656

15. Decurtins S, Gutlich P, Hasselbach KM, Hauser A, Spiering H (1985) Inorg Chem 24:2174

16. Decurtins S, Gutlich P, Kohler CP, Spiering H, Hauser A (1984) Chem Phys Lett 105:1

17. Kahn O, Martinez CJ (1998) Science 279:44

18. Gütlich P, Goodwin HA (2004) Spin Crossover in Transition Metal Compounds I-III. Topics in Current Chemistry, vol 233-235. Springer, Berlin

19. Linares J, Codjovi E, Garcia Y (2012) Sensors 12:4479

20. Dugay J, Gimenez-Marques M, Kozlova T, Zandbergen HW, Coronado E, van der Zant HSJ (2015) Adv Mater 27:1288

21. Zhu L, Zou F, Gao JH, Fu YS, Gao GY, Fu HH, Wu MH, Lu JT, Yao KL (2015) Nanotechnology 26:315201

22. Franke PL, Groeneveld WL (1981) Transit Metal Chem 6:54

23. Franke PL, Haasnoot JG, Zuur AP (1982) Inorg Chim Acta 5

24. Grunert CM, Weinberger P, Schweifer J, Hampel C, Stassen AF, Mereiter K, Linert W (2005) J Mol Struct 733:41

25. Stassen AF, Grunert M, Dova E, Müller M, Weinberger P, Wiesinger G, Schenk H, Linert W, Haasnoot JG, Reedijk J (2003) Eur J Inorg Chem 12:2273-2282

26. Absmeier A, Bartel M, Carbonera C, Jameson GNL, Werner F, Reissner M, Caneschi A, Letard JF, Linert W (2007) Eur J Inorg Chem 19:3047-3054

27. Quesada M, Kooijman H, Gamez P, Costa JS, van Koningsbruggen PJ, Weinberger P, Reissner M, Spek AL, Haasnoot JG, Reedijk J (2007) Dalton Trans 46:5434-5440

28. Hassan N, Weinberger P, Mereiter K, Werner F, Molnar G, Bousseksou A, Valtiner M, Linert W (2008) Inorg Chim Acta 361:1291

29. Koren AO, Gaponik PN, Ivashkevich OA, Kovalyova TB (1995) Mendeleev Commun 5:10

30. Klapötke TM, Stein M, Stierstorfer J (2008) Z Anorg Allg Chem 634:1711

31. Klapötke TM, Krumm B, Steemann FX, Steinhauser G (2010) Safety Sci 48:28

32. Steinhauser G, Evers J, Jakob S, Klapötke TM, Oehlinger G (2008) Gold Bull 41:305

33. Weinberger P, Grunert M (2004) Vib Spec 34:175

34. Schweifer J, Weinberger P, Mereiter K, Boca M, Reichl C, Wiesinger G, Hilscher G, van Koningsbruggen PJ, Kooijinan H, Grunert M, Linert W (2002) Inorg Chim Acta 339:297

35. Grunert CM, Schweifer J, Weinberger P, Linert W, Mereiter K, Hilscher G, Müller M, Wiesinger G, van Koningsbruggen PJ (2004) Inorg Chem 43:155 
36. Absmeier A, Bartel M, Carbonera C, Jameson GNL, Weinberger P, Caneschi A, Mereiter K, Letard JF, Linert W (2006) Chem Eur J 12:2235

37. Hassan N, Stelzl J, Weinberger P, Molnar G, Bousseksou A, Kubel F, Mereiter K, Boca R, Linert W (2013) Inorg Chim Acta 396:92
38. Bahari S (2013) Lett Org Chem 10:527

39. Heppekausen J, Klapötke TM, Sproll SM (2009) J Org Chem $74: 2460$ 